\title{
Is the Reluctance for the Implantation of Right Donor Kidneys Justified?
}

\author{
Denise M. D. Özdemir-van Brunschot ${ }^{1}$ - Cees J. H. M. van Laarhoven ${ }^{1}$ • \\ Michel F. P. van der Jagt ${ }^{1}$ Andries J. Hoitsma ${ }^{2}$ Michiel C. Warlé ${ }^{1}$
}

Published online: 29 August 2015

(c) The Author(s) 2015. This article is published with open access at Springerlink.com

\begin{abstract}
Background The lengths of right renal veins are shorter when compared to their left counterparts. Since the implantation of kidneys with short renal veins is considered more challenging, many surgeons prefer left kidneys for transplantation. Therefore, our hypothesis is that the implantation of right kidneys from living and deceased donors is associated with more technical graft failures as compared to left kidneys.

Methods Two consecutive cohorts of adult renal allograft recipients of living $(n=4.372)$ and deceased $(n=5.346)$ donor kidneys between January 1, 2000 and January 1, 2013 were analyzed. Data were obtained from the prospectively maintained electronic database of the Dutch Organ Transplant Registry. Technical graft failure was defined as failure of the renal allograft within 10 days after renal transplantation without signs of acute rejection. Results In the living donor kidney transplantation cohort, the implantation of right donor kidneys was associated with a higher incidence of technical graft failure (multivariate analysis $p=0.03$ ). For recipients of deceased donor kidneys, the implantation of right kidneys was not significantly associated with technique-related graft failure (multivariate analysis $p=0.16$ ).

Conclusions Our data show that the implantation of right kidneys from living donors is associated with a higher incidence of technique-related graft failure as compared to left kidneys.
\end{abstract}

\section{Abbreviations \\ BMI Body mass index \\ CIT Cold ischemia time \\ DBD Donation after brain death \\ DCD Donation after cardiac death \\ LDN Laparoscopic donor nephrectomy}

Denise M. D. Özdemir-van Brunschot

denise.ozdemir-vanbrunschot@ radboudumc.nl

1 Division of Vascular and Transplant Surgery, Department of Surgery, Radboud University Nijmegen Medical Center, Geert Grooteplein-Zuid 10, 6525 GA Nijmegen, The Netherlands

2 Department of Nephrology, Radboud University Medical Center, Nijmegen, The Netherlands
WIT1 First warm ischemia time

WIT2 Second warm ischemia time

\section{Introduction}

The general opinion is that the implantation of renal allografts with shorter renal veins is technically more challenging. Since right kidneys have shorter renal veins, right kidneys might be associated with technique-related complications. Therefore, many surgeons prefer left kidneys for transplantation. Regarding living donor kidney transplantation, most centers prefer the selection of left kidneys.

In 1995, laparoscopic retrieval of donor kidneys was introduced by Ratner et al. [1], and nowadays, laparoscopic donor 
nephrectomy (LDN) has gradually become "gold standard" for kidney retrieval $[2,3]$. However, laparoscopic procurement of the donor kidney also has several disadvantages as compared to the open technique, e.g., longer first warm ischemia time and operation time. Additionally, the use of the endo-vascular stapler results in loss of length of the renal vein. The right renal vein loses approximately $1.0-1.5 \mathrm{~cm}$ in length [4]. With regard to living donor kidney transplantation, two previously performed studies reported a possible association between the use of right living donor kidneys and venous thrombosis [5, 6], whereas other studies could not confirm this [7-14]. A recently performed systematic review with meta-analysis comparing left versus right living donor kidneys, observed a borderline significant increase in the incidence of venous thrombosis for right donor kidneys [15]. However, results from this metaanalysis should be interpreted with caution due to significant heterogeneity, and publication and selection bias.

Since renal allografts from deceased donors generally have a renal vein with a caval patch attached, the issue of right kidneys with short renal veins does, in theory, not exist in deceased donor kidney transplantation. Some studies showed a significant impact of right deceased donor kidneys on the incidence of vascular complications [1618], whereas other studies did not [19-24].

We hypothesize that the implantation of right living donor kidneys is associated with a higher incidence of technique-related graft failures as compared to left kidneys, whereas the use of right kidneys from deceased donors does not significantly compromise technique-related outcome. To address this hypothesis, we analyzed a large consecutive cohort of kidney transplant recipients included in the Dutch Organ Transplant Registry (NOTR).

\section{Materials and methods}

\section{Patients}

We performed an analysis of all consecutive, living, and deceased donor, renal transplantations in adult recipients, performed between January 1, 2000 and January 1, 2014 in the Netherlands. Data were obtained from a prospectively maintained electronic database by the Dutch Organ Transplant Registry (NOTR, Dutch Transplant Foundation, Leiden, the Netherlands). The following donor and recipient characteristics and surgical parameters were extracted from the database: donor age, gender, body mass index (BMI), and donation after cardiac or brain death (DCD or DBD); recipient age, gender, BMI, smoker, diabetes mellitus, history of vascular events, previous renal transplantation(s), number of arteries, first and second warm ischemia times (respectively, WIT1 and WIT2), cold ischemia time (CIT), and center of implantation (anonymous).

\section{Surgery}

Living donor kidneys were procured by laparoscopic and open donor nephrectomy. Initially, most centers used the open technique. During the following years, most centers gradually replaced open donor nephrectomy by laparoscopic kidney procurement. Nowadays, most centers prefer either transperitoneal LDN or hand-assisted transperitoneal LDN. In the majority of centers, left LDN is preferred over right LDN.

For deceased donors, the kidney is procured by an open approach and, when possible, a caval patch is attached.

\section{Outcome measures}

Technical failure was the main outcome and was defined as graft failure within 10 days without signs of acute rejection. For some patients, the reason of graft failure was characterized as "primary non-function" (PNF) or "non-viable kidney" (NVK). PNF was defined as renal allograft which was good perfused but never functioned; NVK was defined as a poorly perfused renal allograft which also failed to function.

For these patients, it is difficult, if not impossible, to distinguish between technical failure or graft failure due to other factors, e.g., prolonged CIT. Therefore, separate analyses were performed: analyses excluding the patients with graft failure due to PNF or NVK and analyses including these patients.

Secondary outcomes included second warm ischemia time (WIT2) and delayed graft function (DGF). WIT2 was defined as the time from removal of the renal allograft from the ice until revascularization of the kidney; DGF was defined as the need for dialysis in the first week [25].

\section{Statistical analysis}

Continuous variables were given as mean and standard deviation and compared using Students' $t$ test. Categorical data were given as absolute number and percentages and were compared using $\chi^{2}$ tests. To identify possible confounding factors, logistic regression was performed. Factors associated with kidney side (defined as $p<0.15$ ) were included in the multiple regression analysis. Kaplan-Meier analysis with log-rank coefficient and Cox regression analysis was used to compare long-term graft survival. $p$ values $<0.05$ were considered significant.

\section{Results and discussion}

From January 1, 2000 and January 1, 2014, 9.718 consecutive renal transplantations were performed in adult recipients. In total, 4.372 renal transplantations with kidneys from living donors and 5.346 from deceased donors 
were performed. Demographics of donors and recipients are depicted in Tables 1 and 2. Since most centers prefer the implantation of left kidneys, for living donors, more left kidneys were procured (3097 vs 1275). For deceased donors, the number of recovered left and right kidneys was comparable (2.753 vs 2.593$)$.

\section{Living donors}

For living donors, in both uni- and multivariate analyses, the implantation of right renal allografts was significantly ( $p=0.01$ and $p=0.03$ ) associated with the occurrence of technical failure (excluding NVK and PNF), Tables 1 and
3. We also observed a significant association between the implantation of right kidneys and technical failure including cases with PNF and NVK (univariate analysis $p<0.01$ and multivariate analysis $p=0.01$, data not shown.

Separate analyses were performed including only PNF as technical failure (univariate analysis $p<0.01$ and multivariate analysis $p=0.01$ ) and including only NVK (univariate analysis $p<0.01$ and multivariate analysis $p=0.03$ ).

Right renal allografts were associated with a prolonged WIT2 (30.1 vs $27.6 \mathrm{~min}, p<0.01)$ and a significantly higher creatinine level at 3 months (145 vs 134 micromol/ $1, p<0.01)$ when compared to their left counter parts.

Table 1 Left versus right renal allograft (living donors): donor and recipient demographics and allograft functioning

\begin{tabular}{|c|c|c|c|}
\hline & $\begin{array}{l}\text { Left kidney } \\
(n=3097)\end{array}$ & $\begin{array}{l}\text { Right kidney } \\
(n=1275)\end{array}$ & $p$ value \\
\hline \multicolumn{4}{|l|}{ Donor characteristics } \\
\hline Age (year) & $51.5(\mathrm{SD} 11.6)$ & $50.7(\mathrm{SD} 12.5)$ & 0.05 \\
\hline Male gender & $1.375(44.4 \%)$ & $553(43.4 \%)$ & 0.54 \\
\hline BMI $\left(\mathrm{kg} / \mathrm{m}^{2}\right)$ & $26.0(4.1)$ & $25.8(\mathrm{SD} 4.1)$ & 0.35 \\
\hline Multiple arteries & $83(13.2 \%)$ & $14(9.0 \%)$ & 0.16 \\
\hline \multicolumn{4}{|l|}{ Recipient } \\
\hline Age (year) & 48.1 (SD 13.9) & $47.2(\mathrm{SD} \mathrm{14.4)}$ & 0.04 \\
\hline Male gender & $1.891(61.1 \%)$ & $773(60.6 \%)$ & 0.79 \\
\hline $\operatorname{BMI}\left(\mathrm{kg} / \mathrm{m}^{2}\right)$ & $25.1(\mathrm{SD} 4.1)$ & $24.9(\mathrm{SD} 4.3)$ & 0.06 \\
\hline Smoker & $443(17.9 \%)$ & $209(19.7 \%)$ & 0.20 \\
\hline Diabetes mellitus & $325(13.2 \%)$ & $139(13.0 \%)$ & 0.89 \\
\hline Vascular event & $247(9.0 \%)$ & $84(7.4 \%)$ & 0.01 \\
\hline Duration dialysis (days) & $473(677)$ & $496(713)$ & 0.32 \\
\hline \multicolumn{4}{|l|}{ Surgical parameters } \\
\hline Retransplantation & $358(11.6 \%)$ & $168(13.2 \%)$ & 0.14 \\
\hline WIT2 (min) & $27.6(\mathrm{SD} 12.0)$ & 30.1 (SD 13.6) & $<0.00$ \\
\hline CIT (min) & 157 (SD 107) & 162 (SD 93) & 0.20 \\
\hline \multicolumn{4}{|l|}{ Renal outcome } \\
\hline Technical failure $^{\mathrm{a}}$ & $23(0.7 \%)$ & $21(1.6 \%)$ & 0.01 \\
\hline Vascular problems & $21(0.7 \%)$ & $19(1.5 \%)$ & \\
\hline Urological & $1(0.0 \%)$ & $0(0.0 \%)$ & \\
\hline Other & $0(0.0 \%)$ & $2(0.1 \%)$ & \\
\hline Technical failure ${ }^{\mathrm{b}}$ & $26(0.8 \%)$ & $27(2.1 \%)$ & $<0.00$ \\
\hline PNF & $3(0.1 \%)$ & $6(0.5 \%)$ & \\
\hline NVK & $0(0.0 \%)$ & $0(0.0 \%)$ & \\
\hline \multicolumn{4}{|l|}{ Creatinine } \\
\hline Month $3 \mu \mathrm{mol} / \mathrm{l}$ & $134(\mathrm{SD} 74)$ & 145 (SD 116) & $<0.00$ \\
\hline Year $1 \mu \mathrm{mol} / 1$ & 137 (SD 78) & $135(\mathrm{SD} 61)$ & 0.58 \\
\hline DGF & $77(2.6 \%)$ & $27(2.1 \%)$ & 0.58 \\
\hline
\end{tabular}

$B M I$ body mass index, $C I T$ cold ischemia time, $D G F$ delayed graft function, $P N F$ primary non-function, $N V K$ non-viable kidney, WIT2 second warm ischemia time

a Excluding "primary non-function" and "non-viable kidneys"

b Including "primary non-function" and "non-viable kidneys" 
Table 2 Left versus right renal allograft (deceased donors): donor and recipient demographics and allograft functioning

Left kidney $\quad$ Right kidney $\quad p$ value

$(n=2753) \quad(n=2593)$

Donor characteristics

\begin{tabular}{|c|c|c|c|}
\hline Age (year) & 47.7 (SD 15.4) & $48.4(\mathrm{SD} 15.4)$ & 0.13 \\
\hline Male gender & $1.455(52.9 \%)$ & $1.344(51.8 \%)$ & 0.46 \\
\hline BMI $\left(\mathrm{kg} / \mathrm{m}^{2}\right)$ & $25.0(\mathrm{SD} 4.4)$ & $25.1(\mathrm{SD} 4.4)$ & 0.37 \\
\hline $\mathrm{DCD}$ & $1051(38.2 \%)$ & $1025(39.5 \%)$ & 0.31 \\
\hline Multiple arteries & $555(20.3 \%)$ & $550(21.3 \%)$ & 0.36 \\
\hline \multicolumn{4}{|l|}{ Recipient characteristics } \\
\hline Age (year) & $51.9(\mathrm{SD} 13.2)$ & $52.5(13.0)$ & 0.07 \\
\hline Male gender & $1.629(59.2 \%)$ & $1.558(60.1 \%)$ & 0.50 \\
\hline BMI $\left(\mathrm{kg} / \mathrm{m}^{2}\right)$ & $25.5(4.3)$ & $25.3(\mathrm{SD} 4.3)$ & 0.85 \\
\hline Smoker & $397(20.2 \%)$ & $406(21.2 \%)$ & 0.46 \\
\hline Diabetes mellitus & $425(21.0 \%)$ & $323(16.3 \%)$ & $<0.00$ \\
\hline History of vascular event & $297(13.6 \%)$ & $273(13.1 \%)$ & 0.65 \\
\hline Duration of dialysis (days) & $1.559(1010)$ & $1.576(996)$ & 0.58 \\
\hline \multicolumn{4}{|l|}{ Surgical parameters } \\
\hline Retransplantation & $442(16.1 \%)$ & $417(16.1 \%)$ & 0.98 \\
\hline WIT1 (excluding DBD) (min) & $15.8(10.2)$ & $16.1(10.0)$ & 0.51 \\
\hline WIT2 (min) & $32.4(13.6)$ & $34.5(15.2)$ & $<0.00$ \\
\hline CIT (min) & $1071(\mathrm{SD} 390)$ & 1116 (SD 387) & $<0.00$ \\
\hline \multicolumn{4}{|l|}{ Graft outcome } \\
\hline Technical failure ${ }^{\mathrm{a}}$ & $52(1.9 \%)$ & $70(2.7 \%)$ & 0.05 \\
\hline Vascular problems & $44(1.6 \%)$ & $67(2.6 \%)$ & \\
\hline Urological & $0(0.0 \%)$ & $1(0.0 \%)$ & \\
\hline Other & $8(.3 \%)$ & $2(0.1 \%)$ & \\
\hline Technical failure $^{\mathrm{b}}$ & $103(3.7 \%)$ & $130(5.0 \%)$ & 0.02 \\
\hline PNF & $46(1.7 \%)$ & $49(1.9 \%)$ & \\
\hline NVK & $5(.2 \%)$ & $11(.4 \%)$ & \\
\hline \multicolumn{4}{|l|}{ Creatinine } \\
\hline Month $3 \mu \mathrm{mol} / 1$ & 170 (SD 164) & 179 (SD 180) & 0.07 \\
\hline Year $1 \mu \mathrm{mol} / 1$ & 155 (SD 89) & 153 (SD 87) & 0.40 \\
\hline DGF & $749(27.3 \%)$ & $820(31.7 \%)$ & 0.12 \\
\hline
\end{tabular}

$B M I$ body mass index, $C I T$ cold ischemia time, DGF delayed graft function, $P N F$ primary non-function, $N V K$ non-viable kidney, WIT2 second warm ischemia time

a Excluding "primary non-function" and "non-viable kidneys"

b Including "primary non-function" and "non-viable kidneys"

After 1 year, creatinine levels were comparable. The implantation of right renal allografts was associated with decreased long-term (log rank $23.351 p<0.01)$ survival for living donor kidneys, Fig. 1. Subsequently, Cox regressions analysis was performed, confirming a significant disadvantage of right renal allografts $(p=0.032)$. Analysis of data per center showed that procurement of left kidneys was preferred for living donors in most centers. In the centers procuring a relatively large proportion of right donor kidneys, the incidence of technical failure was also higher when compared to left kidneys.

\section{Deceased donors}

For deceased donors, the incidence of technical failure, excluding PNF and NVK, was significantly increased for right sided renal allografts in univariate analysis $(p=0.05)$. However, in multivariable analysis, no association could be demonstrated $(p=0.16)$, Tables 2 and 4 . When technical failure included PNF and NVK in univariate analysis, a significant association was found ( $p=0.02$ ) but could not be confirmed in the multivariate analysis $(p=0.09)$, data not shown. For technical failure 


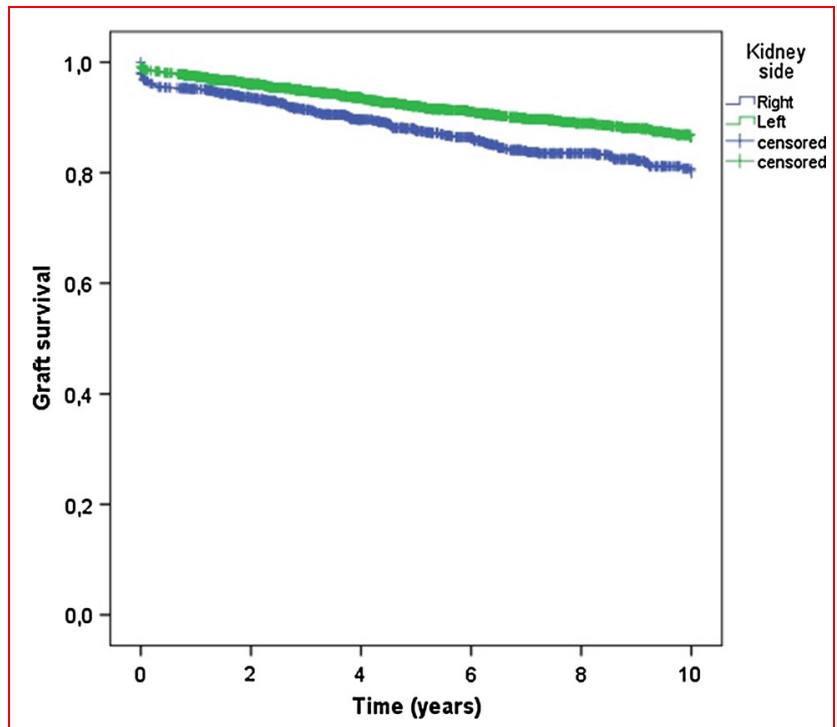

Numbers at risk

\begin{tabular}{lccccc}
\hline & 2 years & 4 years & 6 years & 8 years & 10 years \\
& & & & & \\
\hline Right renal allograft & 1920 & 1410 & 1257 & 1168 & 1069 \\
& & & & & \\
Left renal allograft & 2085 & 1561 & 1465 & 1258 & 1100 \\
& & & & & \\
\hline
\end{tabular}

Fig. 1 Graft survival for right versus left renal allograft, living donors $(\log$ rank $23.35 p<0.000)$ including PNF, no significant association was found when comparing the implantation of right versus left kidney ( $p=0.06$ and $p=0.21$ ); for technical failure including NVK, we only observed a significant association in the univariate analysis $(p=0.02$ and $p=0.07)$.

When right renal allografts were implanted, a significant longer WIT2 (34.5 vs $32.4 \mathrm{~min}, p<0.01$ ) was observed. No significant difference in post-operative creatinine was observed. No association between kidney side and graft survival was observed for kidneys from deceased donors ( $\log$ rank $2.31 p=0.13$ ), Fig. 2. The use of left and right donor kidneys was equally distributed for all centers.

Our data show an association of right kidneys with the occurrence of technical failure for kidneys from living donors. The most plausible explanation is the fact that the creation of a vascular anastomosis with a short renal vein is more difficult and therefore prone to technical problems. Right kidneys from deceased donors usually have a renal vein with a caval patch. This may explain why the association between right kidneys and technical failure was not significant for deceased donor kidneys. The assumption that implantation of right kidneys is technically more challenging is underlined by the fact that the WIT2 for right kidneys was significantly longer. Another explanation could be that the right renal vein is shorter when compared to the left renal vein. The relatively short right renal vein and long renal artery can lead to compression of the renal

Table 3 Univariate and multivariate analyses for technical failure (defined as excluding PNF and NVK) for right versus left renal allografts from living donors

\begin{tabular}{|c|c|c|c|c|}
\hline \multirow[t]{2}{*}{ Parameters } & \multicolumn{2}{|l|}{ Univariate analysis } & \multicolumn{2}{|l|}{ Multivariate analysis } \\
\hline & B $(95 \%$ CI $)$ & $p$ value & B $(95 \%$ CI $)$ & $p$ value \\
\hline Kidney side (right) & $0.447(0.246-0.810)$ & 0.01 & $0.422(0.197-0.902)$ & 0.03 \\
\hline \multicolumn{5}{|l|}{ Donor characteristics } \\
\hline Age (year) & $1.016(0.990-1.042)$ & 0.24 & - & - \\
\hline Male gender & $0.863(0.476-1.563)$ & 0.63 & - & - \\
\hline BMI $\left(\mathrm{kg} / \mathrm{m}^{2}\right)$ & $1.096(1.049-1.145)$ & $<0.00$ & $1.103(1.054-1.154)$ & $<0.00$ \\
\hline Multiple arteries & $0.997(0.000-1.000)$ & 1.00 & - & - \\
\hline \multicolumn{5}{|l|}{ Recipient characteristics } \\
\hline Age (year) & $0.982(0.962-1.003)$ & 0.09 & $0.976(0.951-1.003)$ & 0.08 \\
\hline Male gender & $1.567(0.865-2.839)$ & 0.14 & $2.071(0.971-4.415)$ & 0.06 \\
\hline BMI $\left(\mathrm{kg} / \mathrm{m}^{2}\right)$ & $0.996(0.927-1.071)$ & 0.92 & - & - \\
\hline Smoker & $0.855(0.355-2.059)$ & 0.73 & - & - \\
\hline Diabetes mellitus & $0.566(0.173-1.847)$ & 0.35 & - & - \\
\hline History of vascular event & $1.961(0.816-4.714)$ & 0.13 & $1.606(0.478-5.397)$ & 0.44 \\
\hline Duration of dialysis (days) & $1.000(1.000-1.000)$ & 0.67 & - & - \\
\hline \multicolumn{5}{|l|}{ Surgical parameters } \\
\hline Retransplantation & $0.937(0.368-2.387)$ & 0.89 & - & - \\
\hline WIT1 (min) & $0.000(0.000-1.000)$ & 0.99 & - & - \\
\hline WIT2 (min) & $1.032(1.018-1.047)$ & $<0.00$ & $1.030(1.012-1.049)$ & $<0.00$ \\
\hline CIT (min) & $1.002(1.000-1.003)$ & 0.02 & $1.001(0.998-1.004)$ & 0.51 \\
\hline
\end{tabular}


Table 4 Univariate and multivariate analyses for technical failure (defined as excluding PNF and NVK) for right versus left renal allografts from deceased donors

\begin{tabular}{|c|c|c|c|c|}
\hline \multirow[t]{2}{*}{ Parameters } & \multicolumn{2}{|l|}{ Univariate analysis } & \multicolumn{2}{|l|}{ Multivariate analysis } \\
\hline & $\mathrm{B}(95 \% \mathrm{CI})$ & $p$ value & $\mathrm{B}(95 \% \mathrm{CI})$ & $p$ value \\
\hline Kidney side (right) & $0.694(0.483-0.997)$ & 0.05 & $0.744(0.491-1.124)$ & 0.16 \\
\hline \multicolumn{5}{|l|}{ Donor characteristics } \\
\hline Age (year) & $0.991(0.980-1.002)$ & 0.10 & $0.994(0.981-1.007)$ & 0.36 \\
\hline Gender & $0.900(0.627-1.291)$ & 0.57 & - & - \\
\hline BMI $\left(\mathrm{kg} / \mathrm{m}^{2}\right)$ & $1.000(0.959-1.042)$ & 0.99 & - & - \\
\hline DCD & $0.649(0.453-0.930)$ & 0.02 & $0.593(0.393-0.894)$ & 0.01 \\
\hline Multiple arteries & $1.162(0.757-1.783)$ & 0.49 & - & - \\
\hline \multicolumn{5}{|l|}{ Recipient characteristics } \\
\hline Age (year) & $0.988(0.974-1.001)$ & 0.07 & $0.993(0.977-1.009)$ & 0.37 \\
\hline Male gender & $0.923(0.639-1.335)$ & 0.67 & - & - \\
\hline BMI $\left(\mathrm{kg} / \mathrm{m}^{2}\right)$ & $1.040(.997-1.084)$ & 0.07 & $1.028(0.981-1.077)$ & 0.25 \\
\hline Smoker & $0.919(0.546-1.546)$ & 0.75 & - & - \\
\hline Diabetes mellitus & $0.801(0.459-1.398)$ & 0.44 & - & - \\
\hline History of vascular event & $0.1372(0.807-2.333)$ & 0.24 & - & - \\
\hline Duration of dialysis (days) & $1.000(1.000-1.000)$ & 0.66 & - & - \\
\hline \multicolumn{5}{|l|}{ Surgical parameters } \\
\hline Retransplantation & $1.974(1.315-2.964)$ & $<0.00$ & $2.142(1.338-3.428)$ & $<0.00$ \\
\hline WIT1 (min) (excluding DBD) & $1.019(0.995-1.043)$ & 0.16 & - & - \\
\hline WIT2 (min) & $1.011(1.000-1.022)$ & 0.05 & $1.017(1.006-1.028)$ & $<0.00$ \\
\hline CIT (min) & $1.000(1.000-1.001)$ & 0.08 & $1.000(1.000-1.001)$ & 0.76 \\
\hline
\end{tabular}

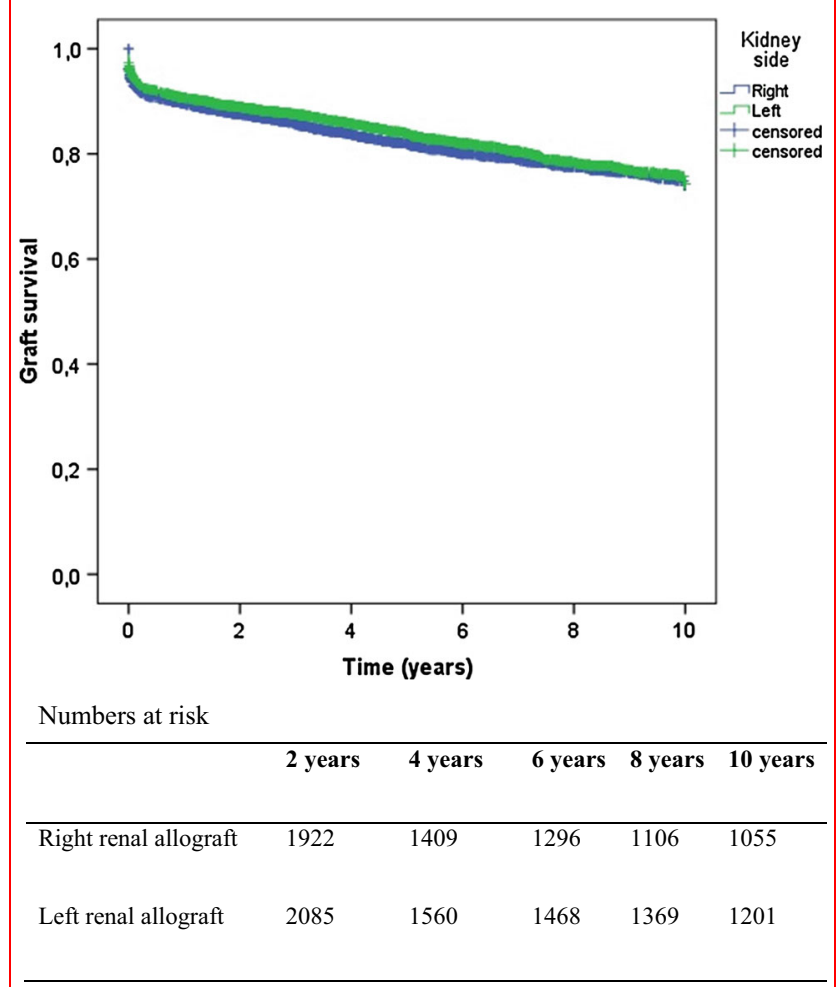

Fig. 2 Graft survival for right versus left renal allograft, deceased donors $(\log \operatorname{rank} 2.31 p=0.13)$ vein in case of swelling, e.g., due to urinary obstruction or perirenal hematoma [16].

Regarding kidneys from deceased donors, there is no consensus about the influence of kidney side on graft outcome and technical failure. Some have observed a significant association of kidney side and graft survival [1618], while others did not [22, 23, 26, 27]. Except for Vacher-Coponat et al. [18], relative small patient series are described in these studies. Vacher-Coponat et al. described adult recipients of 4900 single kidneys, procured from 2450 deceased donors in Australia and New-Zealand. A higher incidence of surgical complications and lower 1-year graft survival of right kidneys were described.

A survey among 96 transplant centers in Northern and Western Europe demonstrated that a majority of the centers preferred left-sided LDN [2]. Individual studies comparing early graft outcome for living donors have shown no significant association of right donor kidneys and venous thrombosis [7-14]. A recent systematic review and metaanalysis demonstrated a significant increased incidence of venous thrombosis, when the right kidney was used (OR 0.35 ; $95 \%$ CI $0.13-0.96, I^{2}=0 \%$ ) [15]. However, this disappeared after sensitivity analysis and therefore the authors concluded that the use of right kidneys did not influence the technical failure rate. This is not in line with the results from our study. A possible explanation for this 
discrepancy may be a type 2 error. Due to the low incidence of technical failure, approximately $0.1-8.2 \%$ [2832 ], a large cohort of renal allograft recipients are necessary to evaluate to association between technical failure and the implantation of a right renal allograft. Our cohort studied three times more patients as compared to the combined cohorts included in the meta-analysis.

Major strength of this study is that a large cohort of patients is studied and the data were obtained from a prospectively maintained database. Limitations are mainly related to the post hoc design of our study. Therefore, information regarding possible confounders, i.e., the experience of the surgeon, right or left fossa, and perioperative hypotension, were not available. Another limitation is the fact that we could not, due to insufficient available data, analyze open and LDN separately. LDN is more likely to shorten the renal vein, and these allografts could therefore be more prone to technical difficulties during implantation.

In conclusion, our data suggest that the implantation of right deceased donor kidneys is not associated with technical failure. The implantation of right living donor kidneys is associated with an increased risk of technical failure, mainly related to the vascular anastomoses.

Acknowledgments The authors are indebted to all colleagues in the various Dutch transplant centers for submitting their data to the Dutch Organ Transplant Registry and to Cynthia Konijn of the Dutch Transplant Foundation (Nederlandse Transplantatie Stichting) for assistance with the data management.

\section{Compliance with ethical standards}

Financial support None.

\section{Conflicts of interests None.}

Open Access This article is distributed under the terms of the Creative Commons Attribution 4.0 International License (http://crea tivecommons.org/licenses/by/4.0/), which permits unrestricted use, distribution, and reproduction in any medium, provided you give appropriate credit to the original author(s) and the source, provide a link to the Creative Commons license, and indicate if changes were made.

\section{References}

1. Ratner LE et al (1995) Laparoscopic live donor nephrectomy. Transplantation 60(9):1047-1049

2. Klop KW et al (2012) Attitudes among surgeons towards livedonor nephrectomy: a European update. Transplantation 94(3):263-268

3. Wilson $\mathrm{CH}$ et al (2011) Laparoscopic versus open nephrectomy for live kidney donors. Cochrane Database Syst Rev (11):CD006124. doi:10.1002/14651858.CD006124.pub2

4. Ratner LE et al (1998) Laparoscopic live donor nephrectomy: technical considerations and allograft vascular length. Transplantation 65(12):1657-1658
5. Mandal AK et al (2001) Should the indications for laparoscopic live donor nephrectomy of the right kidney be the same as for the open procedure? Anomalous left renal vasculature is not a contraindication to laparoscopic left donor nephrectomy. Transplantation 71(5):660-664

6. Ko EY et al (2008) Utility of the endovascular stapler for rightsided laparoscopic donor nephrectomy: a 7-year experience at Mayo Clinic. J Am Coll Surg 207(6):896-903

7. Bettschart V et al (2003) Laparoscopic right nephrectomy for live kidney donation: functional results. Transpl Int 16(6):419-424

8. Posselt AM et al (2004) Laparoscopic right donor nephrectomy: a large single-center experience. Transplantation 78(11):1665-1669

9. Dols LF et al (2009) Laparoscopic donor nephrectomy: a plea for the right-sided approach. Transplantation 87(5):745-750

10. Cheng EY et al (2010) Outcomes of laparoscopic donor nephrectomy without intraoperative systemic heparinization. J Urol 183(6):2282-2286

11. Boorjian S et al (2004) Right laparoscopic live donor nephrectomy: a single institution experience. Transplantation 77(3):437-440

12. Maartense $\mathrm{S}$ et al (2004) Hand-assisted laparoscopic live donor nephrectomy. Br J Surg 91(3):344-348

13. Lind MY et al (2002) Right-sided laparoscopic live-donor nephrectomy: is reluctance still justified? Transplantation 74(7): 1045-1048

14. Gures N et al (2013) Comparison of the right and left laparoscopic live donor nephrectomies: a clinical case load. Eur Rev Med Pharmacol Sci 17(10):1389-1394

15. Liu $\mathrm{N}$ et al (2014) Maximizing the donor pool: left versus right laparoscopic live donor nephrectomy-systematic review and meta-analysis. Int Urol Nephrol 46(8):1511-1519

16. Amezquita $Y$ et al (2008) Risk factors for early renal graft thrombosis: a case-controlled study in grafts from the same donor. Transplant Proc 40(9):2891-2893

17. Bakir N et al (1996) Primary renal graft thrombosis. Nephrol Dial Transplant 11(1):140-147

18. Vacher-Coponat $\mathrm{H}$ et al (2013) Inferior early posttransplant outcomes for recipients of right versus left deceased donor kidneys: an ANZDATA registry analysis. Am J Transplant 13(2):399-405

19. Englesbe MJ et al (2004) Single-center study of technical graft loss in 714 consecutive renal transplants. Transplantation 78(4):623-626

20. Samhan M, Sinan T, Al-Mousawi M (1999) Vascular complications in renal recipients. Transplant Proc 31(8):3227-3228

21. Nagra A et al (2004) The effect of heparin on graft thrombosis in pediatric renal allografts. Pediatr Nephrol 19(5):531-535

22. Phelan PJ et al (2009) Left versus right deceased donor renal allograft outcome. Transpl Int 22(12):1159-1163

23. Salehipour $M$ et al (2008) Comparison of right and left grafts in renal transplantation. Saudi J Kidney Dis Transplant 19(2): 222-226

24. Roodnat JI et al (2003) Ischemia times and donor serum creatinine in relation to renal graft failure. Transplantation 75(6):799-804

25. Yarlagadda SG et al (2008) Marked variation in the definition and diagnosis of delayed graft function: a systematic review. Nephrol Dial Transplant 23(9):2995-3003

26. Chedid MF et al (2013) Living donor kidney transplantation using laparoscopically procured multiple renal artery kidneys and right kidneys. J Am Coll Surg 217(1):144-152 (discussion 152)

27. Bachir BG et al (2011) Evaluation of right versus left laparoscopic donor nephrectomy. Exp Clin Transplant 9(5): 310-314

28. Keller AK, Jorgensen TM, Jespersen B (2012) Identification of risk factors for vascular thrombosis may reduce early renal graft loss: a review of recent literature. J Transplant 2012:793461 
29. Salehipour M et al (2009) Vascular complications following 1500 consecutive living and cadaveric donor renal transplantations: a single center study. Saudi J Kidney Dis Transplant 20(4):570-572

30. Emiroglu R et al (2001) Vascular complications in renal transplantation. Transplant Proc 33(5):2685-2686
31. Phelan PJ et al (2012) Renal allograft loss in the first post-operative month: causes and consequences. Clin Transplant 26(4):544-549

32. Aktas S et al (2011) Analysis of vascular complications after renal transplantation. Transplant Proc 43(2):557-561 